admitted. About 50\% of admitted females and around 30\% of admitted males died. The mean duration of stay at the burn centre was higher for females $(19.17 \pm 23.27)$ compared to males (13.85 \pm 15.29$)$ (p-value 0.0001).

Conclusions Compared to males, females with burn injuries are older and married and likely to have burn injury at home. Males are more likely to have burns at work. Females suffered from higher percentage of surface area of burn. There were more deaths in females.

\section{RESULTS OF A COMMUNITY INTERVENTION TRIAL AIMED AT IMPROVING SAFETY BEHAVIOURS TO PREVENT HOT WATER SCALD BURNS}

Wendy Shields, Elise Perry, Jeffery Zhu, Eileen McDonald, Andrea Gielen. Johns Hopkins Centre for Injury Research And Policy Johns Hopkins Bloomberg School of Public Health

\subsection{6/injuryprev-2016-042156.796}

Background Hot water scalds continue to pose a serious threat in the home, causing over 1500 hospital admissions and 100 deaths each year in the United States. We aimed to determine whether households who participated in an enhanced home safety visit demonstrated improved safety behaviours about hot water compared to homes receiving a standard home visit as part of a community intervention trial.

Methods The temperature of the hot water and self-reported prevention behaviours were recorded at a baseline visit, and retested 6-9 months later in a follow-up visit. Residents whose hot water temperatures remained at an unsafe temperature were asked why they did not adjust the temperatures. Demographic data were also recorded.

Results A total of 708 households participated. There was no significant difference emerged between the two study groups in the proportion of households observed to have adjusted their hot water temperature to safe levels between the baseline and followup visits $(\mathrm{t}=1.24 ; \mathrm{P}=0.22)$. Residents who received the enhanced education were more likely to report testing their hot water temperature $(27 \%$ vs $11 \% ; \mathrm{P}<0.01)$ and turning their hot water temperature below $120^{\circ} \mathrm{F}(43 \%$ vs $32 \% ; \quad \mathrm{P}=0 \quad .08)$. Among those who had unsafe temperature levels and did not reduce the water temperature, the most common reason (26\%) offered was that they "liked it hot."

Conclusions These results suggest that water temperatures remain unsafe in many urban homes. The effect of educational interventions may be mitigated by personal preferences of hot water temperature. Passive intervention such the installation of scald prevention devices may be necessary to reduce risk from hot water.

\section{PILOT STUDY OF A NOVEL PARTNERSHIP FOR HOME FIRE AND CO PREVENTION}

Wendy Shields, Elise Perry, Shannon Frattaroli, Eileen McDonald, Andrea Gielen. Johns Hopkins Centre for Injury Research And Policy Johns Hopkins Bloomberg School of Public Health

\subsection{6/injuryprev-2016-042156.797}

Background Children are at increased risk for death in the event of a home fire. Fire departments have used a number of approaches to increase the uptake of smoke alarms with mixed success. This presentation will describe a pilot study which partnered home visiting nurses with a local fire department in
Phoenix, AZ to instal smoke alarms in high-risk, hard-to-reach homes with young children.

Methods During a regularly scheduled appointment, home visiting nurses with the Nurse-Family Partnership (NFP) informed their clients about an opportunity to get free smoke alarms and recruited participants to the pilot study. Nurses sent a referral to the Phoenix Fire Department (PFD) for a smoke alarm installation. PFD responded to the next NFP appointment and installed long-life battery smoke and $\mathrm{CO}$ alarms in the home and provided safety education. Clients completed a follow up survey 3 months after the PFD installation visit. In-depth interviews were completed with key informants from NFP and PFD to solicit feedback on the program.

Results 58 clients were enrolled into the pilot study. To date, 41 smoke alarm installation visits have been completed and 33 follow up surveys were completed. Before the fire department arrived, 56\% ( $\mathrm{n}=23 / 41$ ) homes had no working smoke alarm. PFD installed 54 smoke alarms into 41 homes; every home had at least one working smoke alarm by the end of the home visit. At follow up, all homes maintained at least one working smoke alarm. Participants increased knowledge scores by 30\%. Interviewees from both NFP and PFD spoke highly of the program and would like the program to continue. The program is consistent with the missions of both NFP and PFD.

Conclusion Partnering home visiting nurses and local fire departments can be a successful partnership to increase the number of homes with working smoke alarms.

\section{FIRE SAFETY PRACTICES IN ASSISTED LIVING AND HOME CARE IN FINLAND}

Tarja Ojala, Satu Pajala, Markus Grönfors, Nina Martikainen, Anne Lounamaa. National Institute for Health and Welfare, Finland

\subsection{6/injuryprev-2016-042156.798}

Background People in vulnerable positions, e.g. elderly or disabled people, substance abuser or mental health patients have an increased risk of becoming fire victims. To avoid this risk fire safety knowledge and good practices are needed for professionals working in the field.

The social and health policy in Finland prioritise assisted living and home care. At the same time the rescue service act stresses that the responsibility of fire safety is on building owners and service providers. Therefore, care professionals are in a novel situation as they are working at clients home and required to take into consideration diverse environment and self-determination of an individual.

The aim of this study was to investigate the fire risk and good practices in assisted living and home care.

Methods The data is from six group interviews done during 2014-2015. Each group included the whole care service chain: the client and one of his/her relatives, care-giver, service provider and planner representatives and fire safety officer. Each group interviewed represented different type of clients and assisted living facilities and service. Interviews took place in various regions in Finland.

Results Each agent at the service chain had ambition to improve fire safety. However, the knowledge among professionals what requires to be done and what others belonging to the same service chain are doing was inadequate. Some safety tools were used but oftentimes the user did not understand enough about their 